\title{
Chondroblastoma-like chondroma of soft tissue: A report of two cases
}

\author{
Daniel J. Zaccarini*1, Zain Badar ${ }^{2}$, Alfredo L. Valente ${ }^{1}$, Gustavo de la Roza ${ }^{1}$ \\ ${ }^{1}$ Department of Pathology, State University of New York Upstate Medical University, New York, United States \\ ${ }^{2}$ Department of Radiology, State University of New York Upstate Medical University, New York, United States
}

Received: July 3, 2017

DOI: $10.5430 /$ jst.v8n1p10
Accepted: August 30, 2017

Online Published: September 26, 2017

\begin{abstract}
Soft tissue chondroma is a benign cartilaginous neoplasm composed of cells with a chondroid phenotype. Chondromas of soft tissue can have variable histological appearances including deposition of calcium, histiocytic reaction, ossification, and myxoid change. One notable variation is the presence of histological features reminiscent of chondroblastoma of the bone, and the term used in this scenario is chondroblastoma-like chondroma of soft tissue. There have been fourteen previous case reports of chondroblastoma-like chondroma of soft tissue, predominantly in the hands; with one case being reported in the base of the skull. We report two cases of chondroblastoma-like chondroma of soft tissue occurring in the hand and foot. To the best of our knowledge this is the first reported case of chondroblastoma-like chondroma of soft tissue in the foot.
\end{abstract}

Key Words: Soft tissue chondroma, Chondroblastoma-like chondroma of soft tissue

\section{INTRODUCTION}

Soft tissue chondroma, also known as extraskeletal chondroma or chondroma of soft parts is a benign cartilaginous neoplasm composed of cells with a chondroid phenotype. Soft tissue chondromas typically occur in the distal extremities, especially the fingers, and less often in the feet, and trunk. Typically, developing in areas associated with tendon sheaths. ${ }^{[1]}$ Fewer cases have been identified in the nasal cavity, paranasal sinuses, larynx, masticatory space, dura, parotid, auricle, and fallopian tube ${ }^{[2-6]}$ The clinical history is usually a slowly growing process that is most often solitary, and rarely present with multiple lesions. They can occur at any age, but they are more frequent in adults with a slight male predominance. ${ }^{[7]}$

Secondary changes can occur microscopically, including de- position of calcium pyrophosphate, granulomatous reaction, myxoid change, enchondral ossification, and dystrophic calcification. ${ }^{[8]}$ If cellular areas containing chondroblasts are identified the term chondroblastoma-like chondroma of soft tissue has been used. Chondroblastoma-like chondromas have been reported in the fingers, metacarpal tendon sheath, and base of the skull. ${ }^{[8-13]}$ The behavior of this variant seems to be similar to other soft tissue chondromas, although limited studies have been performed showing a low rate of recurrence. ${ }^{[8]}$ We review two cases of chondroblastoma-like chondroma of soft tissue.

\section{MAterials AND METHOdS}

Two cases of chondroblastoma-like chondroma of soft parts were retrieved. An additional search in the medical record was performed to evaluate any documented clinical follow-

\footnotetext{
*Correspondence: Daniel J. Zaccarini; Email: zaccarid@ upstate.edu; Address: Department of Pathology, SUNY Upstate Medical University, 750 East Adams Street Syracuse, NY 13210, United States.
} 
up.

\section{Case presentation \\ 3.1 Case 1}

A 57-year-old man with a history of enlarging painless softtissue mass in the left medial second toe, measuring $2.3 \mathrm{~cm}$ in greatest dimension and a recent right third metatarsal fracture. The patient did not report constitutional symptoms. Magnetic resonance imaging (MRI) showed an enhancing soft tissue based lesion on the medial second toe (see Figure 1). The clinical and radiologic differential diagnosis included giant cell tumor of the tendon sheath (GCTTS), peripheral nerve sheath tumor, and less likely sarcoma. The lesion was excised, and microscopic examination revealed numerous variably sized regions of mature, hyaline cartilage without significant atypia. Many of these foci show areas exhibiting mononuclear cells with plump eosinophilic cytoplasm, chicken-wire calcification, scattered giant cells, reminiscent of chondroblastoma (see Figure 2). Histopathologic final diagnosis was chondroblastoma-like chondroma of soft tissue. Recurrence has not been documented in the medical record following one year after resection.

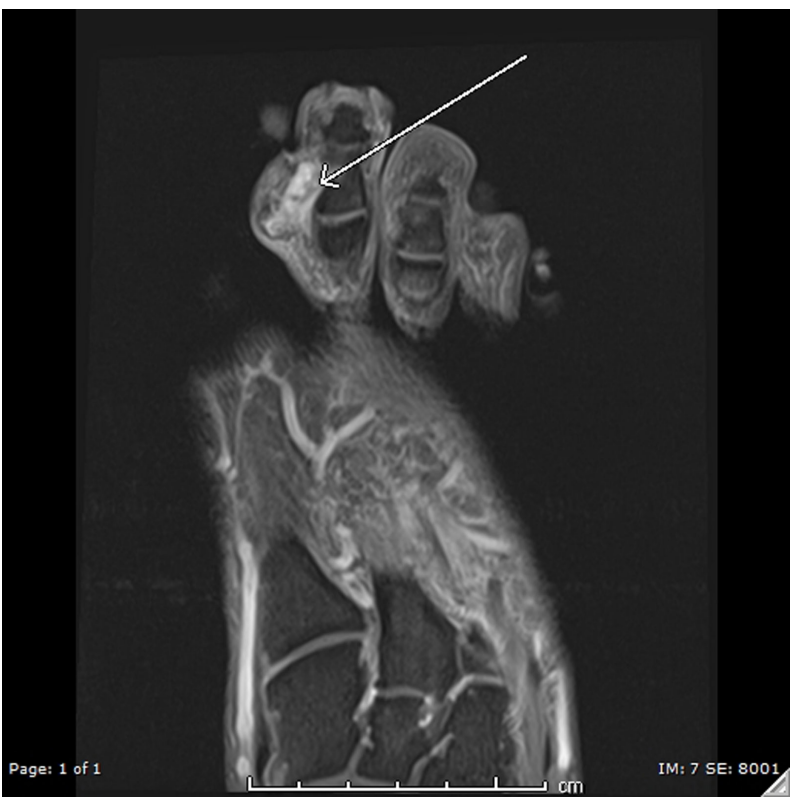

Figure 1. T1 Long axis post contrast images (MRI) show an enhancing lesion (arrow) within the soft tissues in the interphalangeal space between the first and second digits, consistent with an enhancing soft tissue mass

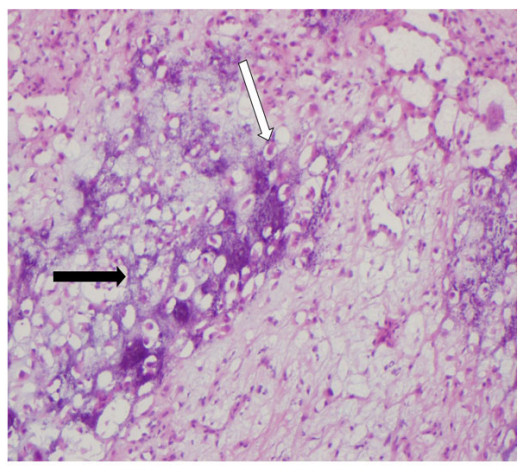

A

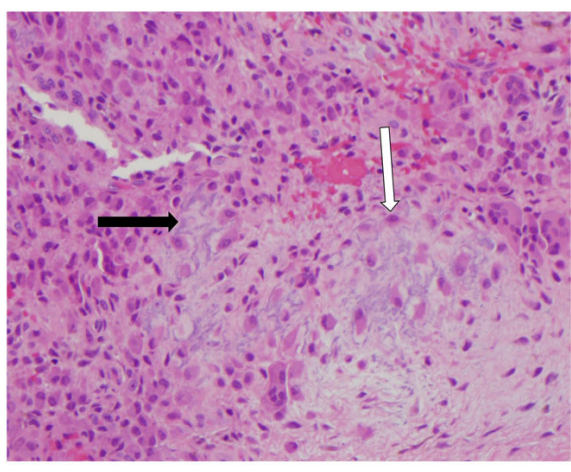

B

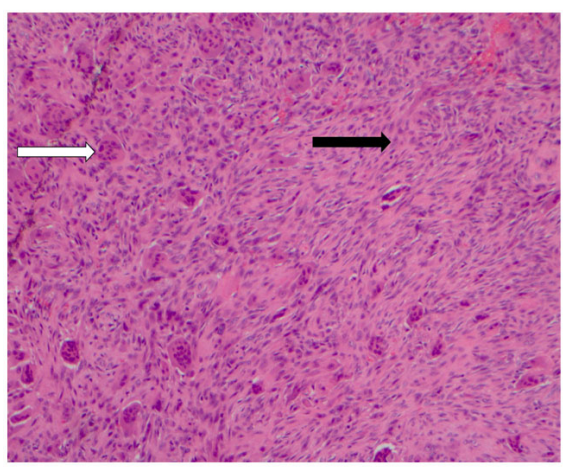

C

Figure 2. Case 1: A) Frozen section showing lace-like calcification (black arrow) around mononuclear cells (white arrow) (Hematoxylin and eosin stain, $20 \times$ ); B) Mononuclear (white arrow) and giant cell proliferation adjacent to a cartilaginous area with lace-like calcification (black arrow) (Hematoxylin and eosin stain, $20 \times$ ); C) Additional areas showed spindle cell proliferation (black arrow) with ovoid nuclei, and giant cells (white arrow) (Hematoxylin and eosin stain, $20 \times$ ).

\subsection{Case 2}

A 30-year-old man presented with a one year history of an enlarging painless soft-tissue mass on the right volar wrist and hand that began gradually. There was no history of trauma or constitutional symptoms. MRI showed a subcutaneous soft tissue mass in the proximal volar aspect of the hand/palm measuring $1.4 \mathrm{~cm} \times 1.4 \mathrm{~cm} \times 1.0 \mathrm{~cm}$ with homogenous enhancement (see Figure 3). The clinical and radiologic differential diagnosis included GCTTS, peripheral nerve sheath tumor, and much less likely a sarcoma. The lesion was excised. Microscopic sections displayed a tumor composed of irregularly shaped lobules of cartilaginous tissue, composed of both mature and myxohyaline cartilage (see Figure 4). At the periphery of the lobules, and also in the fibrous septa separating them, there is a proliferation of cells with small, polygonal, elongated and bean shaped nuclei and moderate amount of eosinophilic cytoplasm. These cells are reminiscent of chondroblasts, and are admixed with multinucleated giant cells. Rare minute areas of mineralization around proliferating cells (chicken wire-like pattern) were noted. Dilated capillary vessels are seen in the interlobular stroma. Histopathologic final diagnosis was consistent with 
chondroblastoma-like chondroma of soft tissue. No reported recurrence in the medical record after one and a half years.

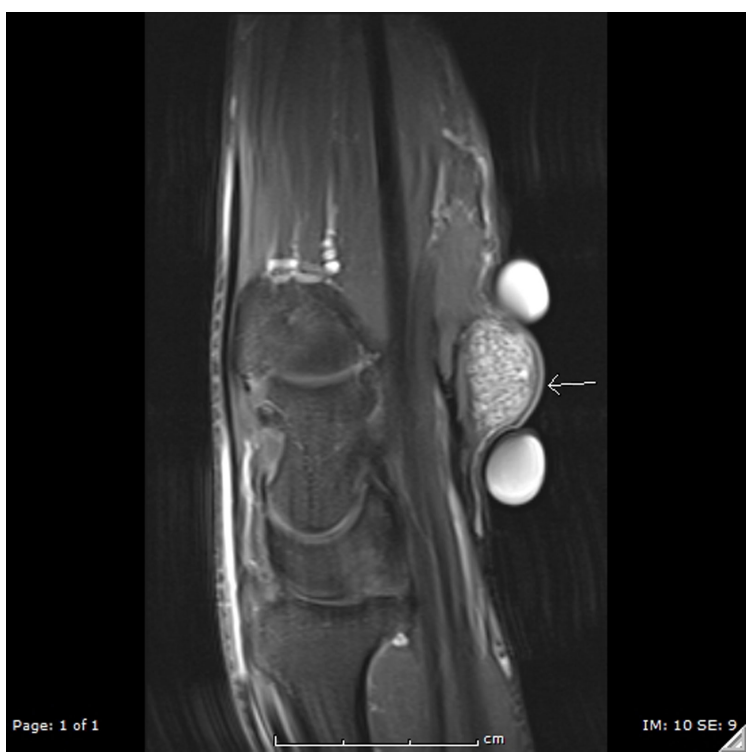

Figure 3. T1 sagittal Fat suppressed post contrast image demonstrates soft tissue lesion (arrow) along the volar aspect of the carpal row with the lesion demonstrating homogenous post contrast enhancement. No osseous involvement is noted.

\section{Discussion}

Chondroblastoma-like chondroma of soft tissue is an extremely rare lesion with only 14 previously reported cases, all but one located in the hand (see Table 1). ${ }^{[8-14]}$ We report one case located in the hand, and one located in the foot. Cates et al. reported that most were in the hands (finger, tendon sheath, and thumb), ranged in size from $1.5 \mathrm{~cm}$ to $2.8 \mathrm{~cm}$, and had variable percentage of chondroblastomalike areas $(10 \%$ to $100 \%){ }^{[8]}$ A case reported in the skull measured $8.5 \mathrm{~cm}$, located in the right masticator space, and extended through the floor of the middle cranial fossa. ${ }^{[9]}$ Herein we report, to the best of our knowledge the first case of chondroblastoma-like chondroma of soft tissue in the foot. Chung et al. initially reported chondroblastoma-like features in a series of soft tissue chondromas, however did not specify the number of cases that had these features. ${ }^{[7]}$ The average age reported in the literature for chondroblastoma-like chondroma of soft tissue is 44.6 years, and with the addition of our two cases is 44.5 years. The first case fits well with the average age, while the second case is slightly young but fits within the range of reported ages (28 to 71 years). Previous reports showed seven males, and seven females, and with our two cases the male to female ratio has increased (1.3: 1). Average previously reported size was $2.8 \mathrm{~cm}$, and with addition of our two cases the average size is $2.7 \mathrm{~cm}$.

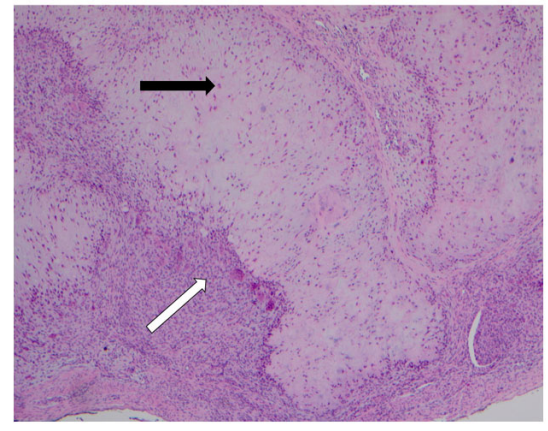

A

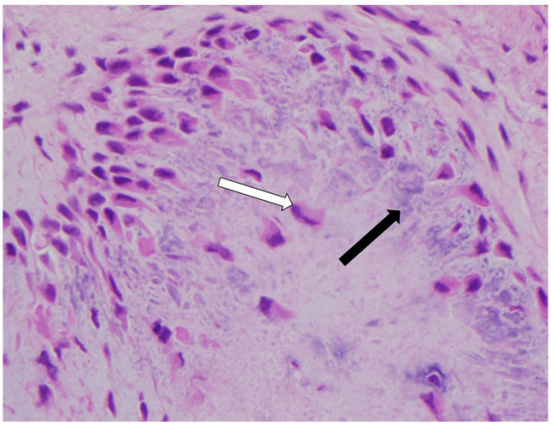

B

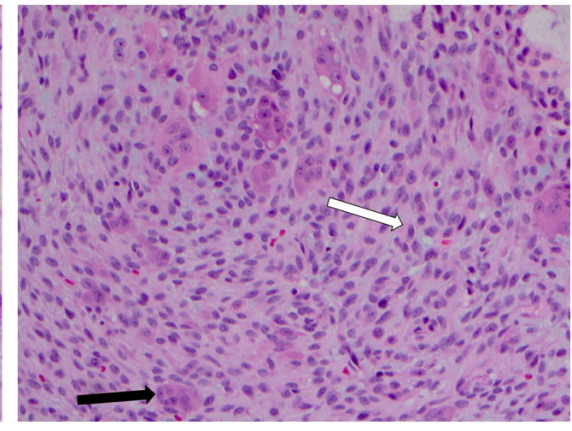

$\mathrm{C}$

Figure 4. A) Bland chondrocytes (black arrow) within the cartilaginous nodules, and an adjacent mononuclear proliferation (white arrow) with giant cells (Hematoxylin and eosin stain, $4 \times$ ); B) Higher power showing mononuclear cells (white arrow) with surrounding calcification (black arrow) (Hematoxylin and eosin stain, $40 \times$ ); C) The proliferation is composed of predominantly moderate to plump ovoid cells (white arrow), with pale eosinophilic cytoplasm, and admixed giant cells (black arrow) (Hematoxylin and eosin stain, $20 \times$ ).

Soft tissue chondromas usually are well-demarcated, firm, and average $1-2 \mathrm{~cm}$ in size, and rarely get larger than $3 \mathrm{~cm}^{\left[{ }^{[7,15]}\right.}$ More than half of cases show lobules of mature hyaline cartilage with well-defined borders. ${ }^{[15]}$ These cartilaginous areas contain small, round chondrocytes with minimal pleomorphism. About one third of reported tumors showed thick calcification at a later stage that may shroud the cartilaginous component. ${ }^{[15]}$ A smaller number of cases may show variable degrees of calcification typically in a "lace-like" pattern at the center of the lesion. ${ }^{[7]}$ Focal myxoid change, ossification, necrosis, and fibrosis have also been reported. ${ }^{[7,8]}$ Cytologic atypia with pleomorphism, binucleation, hyperchromasia, and enlargement may occur as well. ${ }^{[8]} 10 \%$ to $15 \%$ of cases will show a proliferation of 
histiocytes and multinucleated giant cells primarily at the borders of the cartilaginous lobules. ${ }^{[7]}$ Chondroblastomalike features include the presence of mononuclear cells, giant cells, decreased cartilaginous component, and "chicken-wire" calcifications. ${ }^{[8]}$ The chondrocytes typically have abundant eosinophilic cytoplasm with eccentric, kidney-shaped nuclei. ${ }^{[7]}$

Table 1. Previously reported chondroblastoma-like chondromas of soft tissue

\begin{tabular}{llllll}
\hline Case & Age (Years) & Gender & Location & Size & Reference \\
\hline 1 & 34 & M & Finger & 2 & {$[8]$} \\
2 & 44 & M & Metacarpal tendon sheath & 2.5 & {$[8]$} \\
3 & 28 & F & $*$ & 2.8 & {$[8]$} \\
4 & 53 & F & Finger & 2.5 & {$[8]$} \\
5 & 50 & M & Finger flexor tendon & 2.8 & {$[8]$} \\
6 & 44 & F & Thumb & 1.5 & {$[8]$} \\
7 & 71 & M & Thumb & 2.4 & {$[8]$} \\
8 & $*$ & $*$ & $*$ & $*$ & {$[8]$} \\
9 & 33 & M & Skull base & 8.5 & {$[9]$} \\
10 & 49 & F & Finger & 1.8 & {$[10]$} \\
11 & 51 & M & Finger & 4 & {$[11]$} \\
12 & 44 & M & Thumb & 2 & {$[12]$} \\
13 & 47 & F & Finger & 1 & {$[13]$} \\
14 & 32 & F & Thumb & 3 & {$[14]$} \\
\hline
\end{tabular}

Note. * denotes no information available.

Histological differential diagnosis of soft tissue chondroma includes periosteal/juxtacortical chondroma, synovial chondromatosis, tumoral calcinosis, calcifying aponeurotic fibroma, and giant cell tumor of the tendon sheath. Periosteal chondroma can be distinguished radiographically since it is located beneath the periosteum. Synovial chondromatosis can have a similar histological appearance, however its location is in the joints, and identifying a synovial lining helps distinguish the two entities. When calcification is prominent this may lead to the diagnosis of tumoral calcinosis. In comparison to soft tissue chondromas, this entity will not have cartilage, and will have a histiocytic infiltrate. ${ }^{[15]}$ Calcifying aponeurotic fibroma typically affects a younger age group, not more than 25 years, and occurs in the proximal hands rather than the distal digits. ${ }^{[16]}$ The proliferation is usually composed of fibroblasts in a dense stroma. GCTTS is another consideration, however cartilage is not often seen in GCTTS, and comparably the background is usually more collagenized. Foamy macrophages, chronic inflammation, and hemosiderin-laden macrophages also point toward GCTTS. Soft tissue chondromas with myxoid change and atypia create difficulty in distinguishing them from extraskeletal myxoid chondrosarcoma (EMC). Soft tissue chondromas lack the cytologic atypia and are typically seen the hands and feet, which is rare in EMC. ${ }^{[15]}$ In addition, fluorescence in situ hybridization for EWSR1-NR4A fusion can be helpful in supporting EMC. ${ }^{[15]}$ Metastatic chondroblastoma of bone is also another differential, but this is a very rare occurrence.
Differentiating chondroblastoma-like chondroma of soft tissue from a rare soft tissue recurrence of chondroblastoma may not be possible on morphology alone. ${ }^{[8]}$

Chondromas of soft tissue are usually well delineated, and bone involvement is usually not seen radiographcally. ${ }^{[15]}$ Chondroid rings and arcs, bone erosion, and remodeling are characteristic radiographic features. ${ }^{[17]}$ Calcifications can be visualized in roughly $33 \%$ of the soft tissue chondromas on plain radiographs. T1 weighted MRI sequences will show an intermediate signal intensity mass with fluid sensitive MR sequences demonstrating the mass as hyperintense to muscle. The lesion will enhance with contrast. ${ }^{[18]}$

Chondromas of soft tissue are usually treated with excision as was the case in our two case reports. Rarely do soft tissue chondromas recur with one report of recurrence in the hand after nine months. ${ }^{[8]}$ The two cases reported here have no documented recurrence or metastasis. Additionally, a chondroblastoma-like chondroma reported in the base of the skull demonstrated recurrence after seven months. ${ }^{[9]}$ Metastatic disease has not been reported in the literature. To the best of our knowledge this is the first reported case of chondroblastoma-like chondroma of soft tissue occurring in the foot.

\section{CONFLicts OF INTEREST Disclosure}

The authors declare that there is no conflict of interest statement. 


\section{REFERENCES}

[1] Zhang Y, Rosenberg AE. Cartilaginous neoplasms of soft tissue and joints. Diagnostic Histopathology. 2014; 20(5): 200-7. https : //doi.org/10.1016/j.mpdhp.2014.03.006

[2] Aslam M, Haqqani M. Extraskeletal chondroma of parotid gland. Histopathology. 2006; 48(4): 465-7. PMid:16487372. https : //do i.org/10.1111/j.1365-2559.2005.02257.x

[3] Bergmann M, Pinz W, Blasius S, et al. Chondroid tumors arising from the meninges-report of 2 cases and review of the literature. Clin Neuropathol. 2004 Jul-Aug; 23(4): 149-53. PMid:15328878.

[4] De Riu G, Meloni SM, Gobbi R, et al. Soft-tissue chondroma of the masticatory space. Int J Oral Maxillofac Surg. 2007; 36(2): 174-6. PMid:17008056. https ://doi.org/10.1016/j.ijom.2006.07 .006

[5] Kwon H, Kim HY, Jung SN, et al. Extraskeletal chondroma in the auricle. J Craniofac Surg. 2010 Nov; 21(6): 1990-1. PMid:21119479. https://doi.org/10.1097/SCS.0b013e3181f504f5

[6] Varras M, Akrivis C, Tsoukalos G, et al. Tubal ectopic pregnancy associated with an extraskeletal chondroma of the fallopian tube: Case report. Clinical and Experimental Obstretrics and Gynecology. 2008; 35(1): 83. PMid:18390091.

[7] Chung E, Enzinger FM. Chondroma of soft parts. Cancer. 1978; 41(4): 1414-24. https://doi.org/10.1002/1097-0142(1978 04) $41: 4<1414:$ : AID-CNCR2820410429>3.0. C0;2-0

[8] Cates JM, Rosenberg AE, O'Connell JX, et al. Chondroblastoma-like chondroma of soft tissue: An underrecognized variant and its differential diagnosis. Am J Surg Pathol. 2001; 25(5): 661-6. PMid:11342780 https ://doi.org/10.1097/00000478-200105000-00015

[9] Raparia K, Lin JW, Donovan D, et al. Chondroblastoma-like chondroma of soft tissue: Report of the first case in the base of skull.
Ann Diagn Pathol. 2013; 17(3): 298-301. PMid:22743240. https: //doi.org/10.1016/j.anndiagpath.2012.05.005

[10] Kuprys TK, Bindra R, Borys D, et al. Chondroblastoma-like chondroma of the hand: Case report. J Hand Surg. 2014; 39(5): 933-6. PMid:24656394. https ://doi.org/10.1016/j.jhsa.2014.01 .046

[11] Yamada T, Irisa T, Nakano S, et al. Extraskeletal chondroma with chondroblastic and granuloma-like elements. Clin Orthop. 1995; 315: 257-61. https://doi.org/10.1097/00003086-1995060 00-00031

[12] Isayama T, Iwasaki H, Kikuchi M. Chondroblastomalike extraskeletal chondroma. Clin Orthop. 1991; 268: 214-7. PMid:2060211.

[13] Lee JW, Kim DS, Kim MK, et al. Chondroblastoma-like extraskeletal chondroma: A case report. Korean Journal of Pathology. 1999; 33(1): 55-8.

[14] Navya BN, Ranganath N, Karumbaiah P, et al. Chondroblastoma-like extraskeletal chondroma of the hand: A rare case report. Sch. J. App. Med. Sci. 2014; 2(4D): 1428-30.

[15] Goldblum JR, Weiss SW, Folpe AL. Enzinger and Weiss's soft tissue tumors. Elsevier Health Sciences; 2013.

[16] Bridge J, Hogendoorn P, Bridge JA, et al. WHO classification of tumours of soft tissue and bone. International Agency for Research on Cancer; 2013.

[17] Le Corroller T, Bouvier-Labit C, Champsaur P. Diffuse mineralization of forearm extraskeletal chondroma. Joint Bone Spine. 2008; 75(4): 479-81. PMid:18439866. https://doi.org/10.1016/j . jbspin. 2007.06 .019

[18] Weiss S, Goldblum J. Cartilaginous soft tissue tumors. Enzinger and Weiss's Soft Tissue Tumors, ed. 2001; 5: 1017-36. 